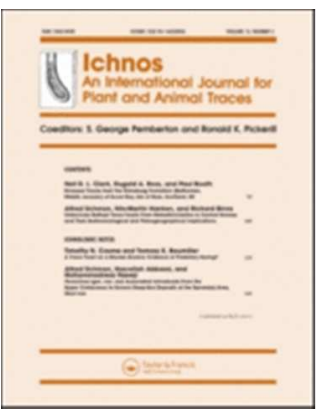

\title{
HUMANS RUNNING AT STADIUMS AND BEACHES AND THE ACCURACY OF SPEED ESTIMATIONS FROM FOSSIL TRACKWAYS
}

\begin{tabular}{|r|l|}
\hline Journal: & Ichnos \\
\hline Manuscript ID: & GICH-2011-0030.R1 \\
\hline Manuscript Type: & Original Article \\
\hline Date Submitted by the Author: & n/a \\
\hline Complete List of Authors: & $\begin{array}{l}\text { Ruiz, Javier; universidad Complutense de Madrid, Departamento de } \\
\text { Geodinamica } \\
\text { Torices, Angelica; Universidad Complutense de Madrid, Departamento de } \\
\text { Paleontologia }\end{array}$ \\
\hline Keywords: & $\begin{array}{l}\text { Vertebrate tracks, dinosaurs < Trace-Making Animals, mammals < Trace- } \\
\text { Making Animals }\end{array}$ \\
\hline
\end{tabular}

SCHOLARONE $^{\mathrm{m}}$

Manuscripts 


\title{
HUMANS RUNNING AT STADIUMS AND BEACHES AND
} THE ACCURACY OF SPEED ESTIMATIONS FROM FOSSIL

\section{TRACKWAYS} \\ ${ }^{1}$ Departamento de Geodinámica, Facultad de Ciencias Geológicas, Universidad \\ Complutense de Madrid, 28040 Madrid, Spain \\ ${ }^{2}$ Centro de Biología Molecular, CSIC-Universidad Autónoma de Madrid, \\ 28049 Cantoblanco, Madrid, Spain \\ ${ }^{3}$ Departamento de Paleontología, Universidad Complutense de Madrid, \\ 28040 Madrid, Spain \\ ${ }^{4}$ Department of Biological Sciences, Faculty of Science, CW405 Biological Sciences \\ Building, University of Alberta, Edmonton, Alberta, Canada T6G 2E9 \\ * Corresponding author: E-mail: jaruiz@geo.ucm.es \\ Phone: +34913944821; Fax: +34913944631 .
}

Key Words: Vertebrate tracks; Trace-making animals: dinosaurs; Trace-making animals: mammals

Running Head: Speed estimations from trackways

URL: http://mc.manuscriptcentral.com/gich Email: ichnos.journal@gmail.com 


\begin{abstract}
The concept of dynamic similarity, between mechanical properties of vertebrates and engineered structures, has served in previous work to suggest that there is a power law relationship between vertebrate speed and stride length. This relationship, with some additional assumptions about hind limb height, in turn has permitted the calculation of speeds from fossil trackways of dinosaurs. However, there are claims that uncertainties are large. In this work we analyze the accuracy of speed calculations for fossil vertebrates based on fossil trackways by using data derived from both athletic competitions and an experiment with humans walking and running on a beach. Our results show that, although there are somewhat different running regimes, in general terms human speed can be described in a simple way and differences between observed and predicted speeds usually are no more than around 10-15\%. Thus, while recognizing that some uncertainty remains in the estimation of hind limb height, we conclude that reliable speed calculations can be obtained from vertebrate fossil trackways. Our results also show that very reliable speed estimates can be obtained from human fossil trackways directly from stride length measurements.

Key Words: Vertebrate tracks; Trace-making animals: dinosaurs; Trace-making animals: mammals
\end{abstract}

\title{
INTRODUCTION
}

Calculating speeds from fossil trackways has become a common procedure in vertebrate and human paleontology (e.g., Alexander, 1976, 1984; Farlow, 1981; Thulborn, 1982; Weems, 2006; Webb, 2007; Raichlen et al., 2008). Central to the majority of these studies is the concept of dynamic similarity, which proposes that 
living and extinct animals share common basic mechanical properties with structures used in engineering (Alexander, 1976). Alexander (1976) suggested that the Froude number, a non-dimensional parameter usually used in naval engineering, also can be used to analyze the mode of displacement of different terrestrial vertebrates, including humans. For this purpose, Alexander (1976) proposed to define the Froude number as $v^{2} /(g h)$, where $v$ is the animal's speed, $g$ is the force of gravity at the Earth's surface, and $h$ is the total height of its hind limbs, measured from the ground to the acetabulum (pelvic articulation of the femur). A direct consequence of this line of argument is that an increase in the animal's stride length implies an increase in its speed. This corollary has been used to calculate speeds from stride length measurements taken from fossil trackways.

Alexander (1976) used observations for different kinds of animals, and results from an experiment with three humans walking and running on a beach, to propose that the relationship between the non-dimensional (i.e., relative) stride length $(\lambda / h$, where $\lambda$ is the absolute stride length) and the Froude number follows a power law from which movement speed can be calculated as a function of the stride length. This kind of argument has been widely applied to dinosaur trackways to calculate the speeds of the animals that created these trackways. This has been justified by similarities between the manner of moving of dinosaurs and mammals, humans included (Alexander, 1991), because both of these vertebrate groups have their limbs underneath the body. Moreover, the use of the quotient between stride length and hindlimb height (which must be deduced from the fossil tracks), has been proposed to distinguish between trackways made by a walking or a running animal (Alexander, 1976; Thulborn, 1990). Observed speeds reported for some mammals differ from theoretical predictions by 
factors as large as 1.5 or 2.5 (Bakker, 1987; Alexander, 2006), but it needs to be kept in mind that conclusions based on observations of free-ranging animals require untestable assumptions about their size, weight, and proportions (see Alexander et al., 1977).

Here, we use data derived from athletic competitions and from an extended experiment with walking and running humans to test the proposed proportional relationship between stride length and speed for humans. Our ultimate goal is to analyze the accuracy of speed calculations for fossil vertebrates (including humans) based on fossil trackways. Since humans were included in the analysis of Alexander (1976), more extensive testing of the validity of the relationships obtained by Alexander for humans will greatly improve the reliability of dynamic similarity methodology in general. Finally, we use our results to calculate speeds from a large sample of human fossil trackways found at the upper Pleistocene Willandra Lakes footprint site in Australia.

\section{ALEXANDER'S EQUATION}

The power law relationship between Froude's number and non-dimensional speed found by Alexander (1976) is

$$
\lambda / h \cong 2.3\left[v^{2} /(g h)\right]^{0.3}
$$

From equation (1), the absolute speed can be calculated as a function of $\lambda$ and $h$,

$$
v \cong 0.25 g^{0.5} \lambda^{1.67} h^{-1.17}
$$

Alexander (1976) also proposed that a terrestrial vertebrate makes the transition from 
walking to running when the $\lambda / h$ ratio exceeds 2.0 . To solve equation (2) from to vertebrate trackways $h$ must be reasonably estimated for the animal that made the tracks (Thulborn, 1982, 1984; Bakker, 1987; Henderson, 2003). Interestingly, speed calculations from evolutionary robotics simulation based on musculoskeletal models of emus, ostriches, humans and five bipedal dinosaurs, are also close to the predictions of equation (1) (Sellers and Manning, 2007).

\section{RELATIONSHIP OF STRIDE LENGTH TO SPEED IN ELITE ATHLETES}

Data from athletic competitions are an excellent source of comparative material because they have been obtained in very well-controlled conditions (for a description of this kind of analysis see Kersting, 1999). Lamentably, these data bear two important deficiencies: 1) stride length and speed measurements are usually restricted to $100 \mathrm{~m}$ races, although some few (albeit very informative) data for 200 and $400 \mathrm{~m}$ races are available, 2) hind limb heights are not taken, although differences in hind limb height among human athletes are relatively small.

Figure 1 shows interval values of $v$ as a function of $\lambda$ for the final races of: men's 100 m, Tokyo 1991 World Championship (Ae et al., 1992), men and women's 100 m, Barcelona 1989 World Cup (Pascua, 1990); men and women's 100 and 200 m, Athens 1997 World Championship (Kersting, 1999); and men and women's $4 \times 400 \mathrm{~m}$ (individual data for seven men and three women), Helsinki 1983 World Championship (Mero et al., 1988). Data for the interval including start from "starting blocks" or running on curves are not included, since they are unnatural. Also represented are theoretical curves obtained from equation (2) for $h=0.86$ and $1.02 \mathrm{~m}$, the extreme values for the human sample used in the experiment described in the next section, and $g$ 
$=9.8 \mathrm{~m} \mathrm{~s}^{-2}$.

The speed data for athletes either are similar to or lower than the range predicted for humans from equation (2). Different stride length/speed data groupings for races of 100 and $400 \mathrm{~m}$ are evident (for a given stride length, each $400 \mathrm{~m}$ speed is lower than its corresponding $100 \mathrm{~m}$ speed), with $200 \mathrm{~m}$ data falling in a somewhat intermediate position. Therefore, speed is non-unique for a given stride length. Rather, speed is dependent on the length of the race. This highlights the importance of stride frequency, a parameter that cannot be obtained for fossil trackways. However, these results could be related to maximized performance in highly trained athletes. In any case, it is worth mentioning that experiments with purebreds horses that are trotting and cantering (a slow gallop with a three-beat gait) have shown that in a certain (equine) stride length range a given stride length may correspond to two different speeds, one a slower one for trot and a faster one for canter (Wickler et al., 2002).

\section{HUMANS WALKING AND RUNNING ON A BEACH}

We have repeated Alexander's (1976) experiments with humans walking and running on a beach, but with a much larger sample. Our experiment was performed at La Griega beach, Colunga (Asturias, Spain), where (appropriately) there are dinosaur trackways in rocky outcrops bordering the beach (García-Ramos et al., 2002; Lockley et al., 2007). The human sample included 14 individuals (7 women and 7 men), mostly students taking the vertebrate paleontology course at the Universidad Complutense de Madrid. Each individual generated five set of data, two for walking, one for fast walking, and two for running on relatively hard ground exposed during low tides.

Figure 2 shows the square-root of the Froude number, as a function of $\lambda / h$, 
derived from data observed in our experiment. This is useful to our purposes, since $\left[v^{2} /(g h)\right]^{0.5}$ can be directly visualized as a non-dimensional (relative) speed. There are three significant features visible in Figure 2: 1) walking data are quite close to the theoretical curve described by equation (2), but there is significantly more scatter in the running data; 2) the transition from walking to running is well defined at $\lambda / h=2.06$, in good accordance with previous work (Alexander, 1976; Thulborn, 1990; Weems, 2006); 3) our data can be fitted (with $R^{2}=0.936$ ) by a power law, from which speed can be calculated,

$$
v=0.226 g^{0.5} \lambda^{1.67} h^{-1.17}
$$

This equation is almost identical to equation (2). Running data also can be separately fitted by a power law, with speed values proportional to $\lambda^{1.32}$, but the fit quality $\left(R^{2}=\right.$ 0.718) is not as good as that obtained for the whole data set from the experiment at La Griega beach.

Figure 3 shows the ratio between observed and theoretical (deduced from equation 2) speeds ( $v_{o b s}$ and $v_{t h}$ respectively) as a function of the non-dimensional stride length, along with mean and standard deviations for these data, which are $1.006 \pm$ 0.116 . Maximum and minimum values of $v_{o b s} / v_{t h}$ are 1.38 and 0.65 , respectively. The variation of our data with respect to theoretical values is therefore generally much less than a factor of 1.5-2.

\section{ATHLETES AND UNTRAINED HUMANS TOGETHER}

Because of the unavailability of hind limb height measurements for elite athletes 
we cannot compare the data from athletic competitions with our experimental data as a function of $\lambda / h$. As an alternative, Figure 4 shows absolute speeds as a function of absolute stride lengths, both for 100, 200 and $400 \mathrm{~m}$ races and for humans walking and running at La Griega beach. Although each set of data can be differentiated by particular values of $v$ vs $\lambda$, the data set taken as a whole fits readily to a power law,

$$
v=0.794 \lambda^{1.67} \text {. }
$$

This equation has an excellent fit quality $\left(R^{2}=0.969\right)$, and is astonishingly close to equation (2) for $h \approx 1 \mathrm{~m}$, which is the case for humans. The derivation of a very similar exponent $(1.67=5 / 3)$ in equations (2), (3) and (4) suggests that it is an inherent property of bipedal movement independent of species, surfaces or training. However, there are differences in the relationship between $v$ and $\lambda$ for each type of running movement (or "races", which include running on a beach). In other words, in spite of different running regimes, taken globally human speed can be described in a simple way.

Figure 5 shows the ratio between observed speeds and speeds predicted by equation (4) (symbolized by $v_{\text {pred }}$ ) for the whole data set included in Figure 4. Mean and standard deviations for $v_{\text {obs }} / v_{\text {pred }}(1.008 \pm 0.130)$ are also shown. Similarly to the above stated relationship between $v$ and $\lambda$, different types of running have particular $v_{\text {obs }} / v_{\text {pred }}$ behavior, with generally lower values for higher stride lengths. Our results indicate that the accuracy of the methodology of Alexander (1976) generally is very good for humans, with differences from theoretical predictions usually around only $10-15 \%$, a higher level of accuracy than previously quoted. Our results also show that equation (4) 
can be used to calculate reliable speeds for humans from stride length, even without knowledge of the height (length) of the hind limb. Finally, since our results obtain a good description of human speed as a function of stride length, future work also considering weights could be useful to evaluate the proposal of Weems (2006) of use the relation between body mass and speed to further refine the Alexander's equation.

\section{A CASE STUDY FOR HUMANS: THE WILLANDRA LAKES FOSSIL}

\section{TRACKWAYS}

Besides supporting the general validity of Alexander's rule for calculating speed from fossil trackways, our results can be used to estimate very reliable speeds from fossil human trackways directly from stride length. Here we use equation (4) to calculate speeds from 22 upper Pleistocene human trackways from the Willandra Lakes region, southeastern Australia, which are dated between 19 and $23 \mathrm{Ka}$ (Webb et al., 2006; Webb, 2007).

Different sizes and weights, and hence different statures and probably ages, as well as different morphologies associated with sex, have been reported (Webb, 2007). Speeds for trackways were calculated (see Table 1) by Webb (2007) by applying the methodology of Charteris et al. (1981) relating foot length, stride length and sex to velocity. Webb concluded that some trackways suggest high speed, with one individual (trackway T8) running at $10.3 \mathrm{~m} \mathrm{~s}^{-1}$, a speed typical of sprint runs and comparable with velocities obtained by elite athletes.

Table 1 also shows speeds calculated from the Willandra Lakes trackways by using equation (4). Our estimated velocities are in general lower than those estimated by Webb (2007). Also, the speed for T8 is reduced to speeds clearly lower than values 
typical of trained athletes. This is much more believable for a non-athlete human than the result obtained by Webb (2007), although it remains true that this individual probably was sprinting. Our results clearly show that the results obtained by Webb (2007), and the methodology of Charteris et al. (1981), overestimate speed in the majority of cases.

\section{CONCLUSIONS}

We have used a large set of human data from different settings to improve the testing of the reliability for humans of the methodology for calculating vertebrate speeds based on dynamic similarity (Alexander, 1976). Our results indicate that the accuracy of this methodology generally is very good for humans, with actual values usually falling within $10-15 \%$ of theoretical predictions with differences from theoretical predictions usually around 10-15\%, a higher level of accuracy than quoted by previous works (e.g., Bakker, 1987; Alexander, 2006). Since data for humans were included in the derivation of the Alexander's (1976) methodology, the present study greatly reinforces the finding that reliable speed calculations can be obtained from fossil trackways. Finally, our results also show that very reliable speeds estimates can be obtained from human fossil trackways directly from stride length measurements without independent knowledge or estimation of the trackmaker's hip height.

\section{ACKNOWLEDGMENTS}

This paper is dedicated to the memory of Nieves López-Martinez. We thank her for his continuous encouragement and support for this project. We thank Arturo Oliver and Jesús Aranaz, of the Escuela Nacional de Entrenadores, Real Federación Española 
de Atletismo, for their help in searching of data derived from analysis of official athletic competitions; Alejandro González, Ricardo Lara, Nieves López-Martinez, Valle López and Ignacio Ruiz-Omeñaca for their logistical support for the experiment at La Griega beach; James Farlow for his comments on an early version of this work; and Robert Weems and an anonymous reviewer for their comments and suggestions. Finally, we thank the students in the vertebrate paleontology course at the Universidad Complutense de Madrid for voluntarily serving as experimental sample. A.T was funded by FECYT and the program "Ayudas para la movilidad postdoctoral en centros extrajeros" during the final stage of this work.

\section{REFERENCES}

Ae. M., Ito, A., and Suzuki, M. 1992. The men's 100 metres. New studies in Athletics 7: $47-52$.

Alexander, R.McN. 1976. Estimates of speeds of dinosaurs. Nature, 261: 129-130.

Alexander, R.McN. 1991. How dinosaurs ran. Scientific American, 261: 130-136.

Alexander, R.McN. 1984. Stride length and speeds for adults, children, and fossil hominids. American Journal of Physical Anthropology, 63: 23-27.

Alexander, R.McN., 2006. Dinosaurs biomechanics. Proceedings of the Royal Society $B, 273: 1849-1855$.

Alexander, R.McN., Langman, V.A., and Jayes, A.S. 1977. Fast locomotion of some large African ungulates. Journal of Zoology, 183: 291-300.

Bakker, R.T. 1987. The return of the dancing dinosaurs. In Czerkas, S.J., and Olson, E.C. (eds.). Dinosaurs Past and Present Volume I. Natural History Museum of Los Angeles County, Los Angeles, pp 38-69. 
Charteris, J., Wall, J.C., and Nottrodt, J.W. 1981. Functional reconstruction of gait from the Pliocene hominid footprints at Laetoli, northern Tanzania. Nature, 290: 496498.

Farlow, J.O. 1981. Estimates of dinosaur speeds from a new trackway site in Texas. Nature, 294: 747-748.

García-Ramos, J.C., Lires, J., and Pinuela, L. 2002. Dinosaurios: Rutas por el Jurásico de Asturias. La Voz de Asturias, Lugones (Siero), 204 p.

Henderson, D.M. 2003. Footprints, trackways and hip heights of bipedal dinosaurstesting hip height predictions with computer models. Ichnos, 10: 99-114.

Kersting, U.G. 1999. Biomechanical analysis of the sprinting events. In Brüggemann, G.P., Koszewski, D., and Müller, H. (eds.). Biomechanical research project Athens 1997. Meyer \& Meyer Sport, Oxford, p. 12-61.

Lockley, M.G., Lires, J., Garcia-Ramos, J.C., Pinuela, L., and Avanzini, M. 2007. Shrinking the World's Largest Dinosaur Tracks: Observations on the Ichnotaxonomy of Gigantosauropus asturiensis and Hispanosauropus hauboldi from the Upper Jurassic of Asturias, Spain. Ichnos, 14: 247-255.

Mero, A., Luhtanen, P., Komi, P., Susanka, P. 1988. Kinematics of top sprint (400m) running in fatigued conditions. Track and Field Quarterly, 88: 42-45.

Pascua, M. 1990. Carreras de velocidad. In Bravo, J. (ed.). Atletismo (I) Carreras y marcha. Comité Olímpico Español, Madrid, p. 25-78.

Raichlen, D.A., Pontzer, H., and Sockol, M.D. 2008. The Laetoli footprints and early hominin locomotor kinematics. Journal of Human Evolution, 54: 112-117.

Sellers, W.I., and Manning, P.L. 2007. Estimating dinosaur maximum running speeds using evolutionary robotics. Proceedings of the Royal Society B, 274: 2711-2716. 
Thulborn, R.A. 1982. Speeds and gaits of dinosaurs. Palaeogeography, Palaeoclimatology, Palaeocology, 38: 227-256.

Thulborn, R.A. 1984. Preferred gaits of bipedal dinosaurs. Alcheringa, 8: 243-252.

Thulborn, R.A. 1990. Dinosaur tracks. Chapman and Hall, London, 410 p.

Webb, S. 2007. Further research of the Willandra Lakes fossil footprint site, southeastern Australia. Journal of Human Evolution, 52: 711-715.

Webb, S., Cupper, M.L., and Robins, R., 2006. Pleistocene human footprints from the Willandra Lakes, southeastern Australia. Journal of Human Evolution, 50: 405413.

Weems, R. 2006. Locomotor speeds and patterns of running behavior in nonmaniraptoriform theropod dinosaurs. In Harris, J.D., Lucas, S.G., Spielmann, J.A., Lockley, M.G., Milner, A.R.C., and Kirkland, J.I. (eds.). The Triassic-Jurassic Terrestrial Transition. New Mexico Museum of Natural History \& Science, Bulletin 37, Alburquerque, p. 379-389.

Wickler, S.J., Hoyt, D.F., Cogger, E.A., McGuire, R. 2002. The cost of transport in an extended trot. Equine Veterinary Journal, Supplement, 34: 126-130.

URL: http://mc.manuscriptcentral.com/gich Email: ichnos.journal@gmail.com 


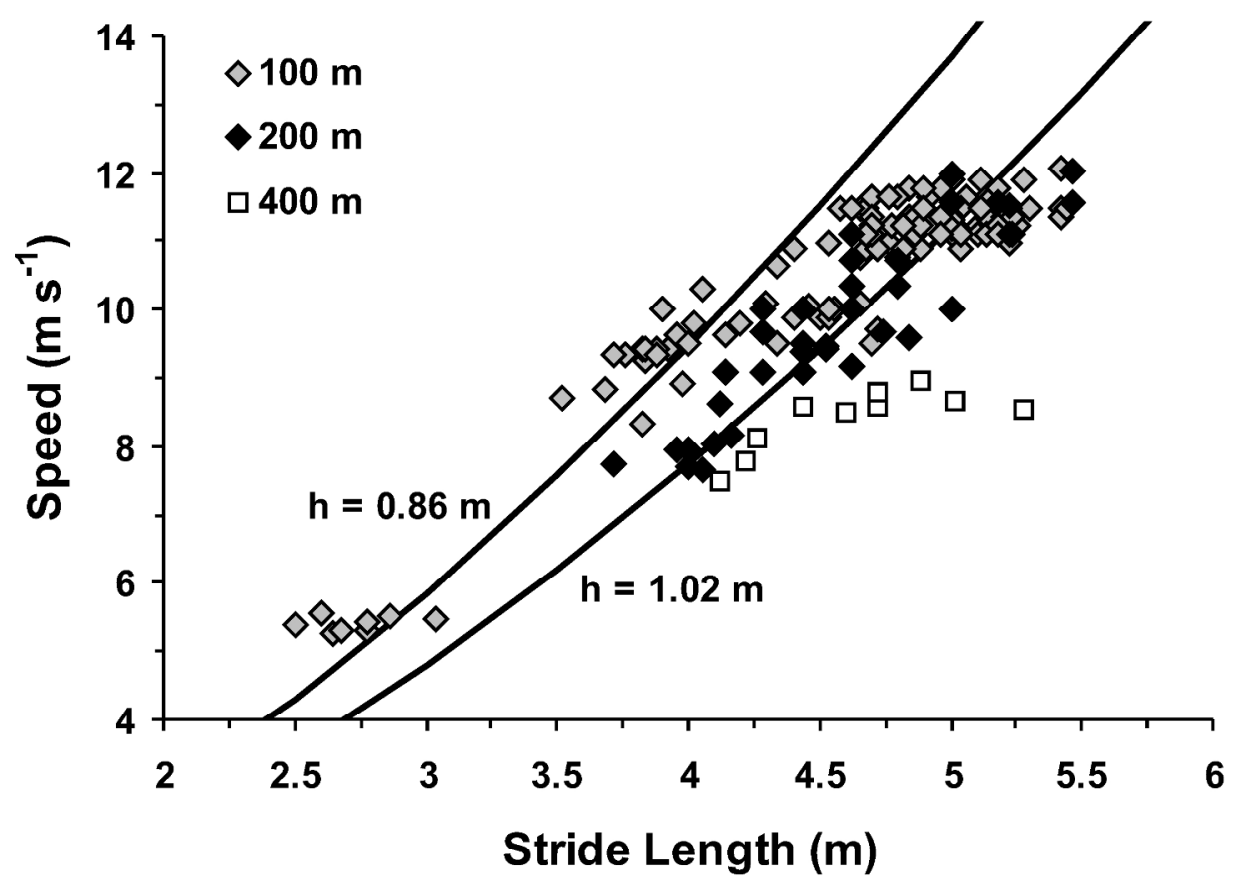

FIGURE 1. Speed as a function of stride length for 100, 200, and $400 \mathrm{~m}$ races (see text for details on specific competition sampled). Original data on the athletic competitions were measured as step amplitude, which is equal to $\lambda / 2$. The lower speed values for the $100 \mathrm{~m}$ correspond to the 10 to $20 \mathrm{~m}$ interval of the final race of men's 100 m of Tokyo 1991 World Championship, the only race for which stride length and speeds are available in ten meters intervals. Remaining $100 \mathrm{~m}$, and all $200 \mathrm{~m}$, data are for twenty meters intervals. Values for the $400 \mathrm{~m}$ correspond to the 328-333 m interval. Predictions from equation (2) (Alexander, 1976) for $\mathrm{h}=0.86$ and $1.02 \mathrm{~m}$ are also shown (black curves). $750 \times 624 \mathrm{~mm}$ (96 x 96 DPI) 


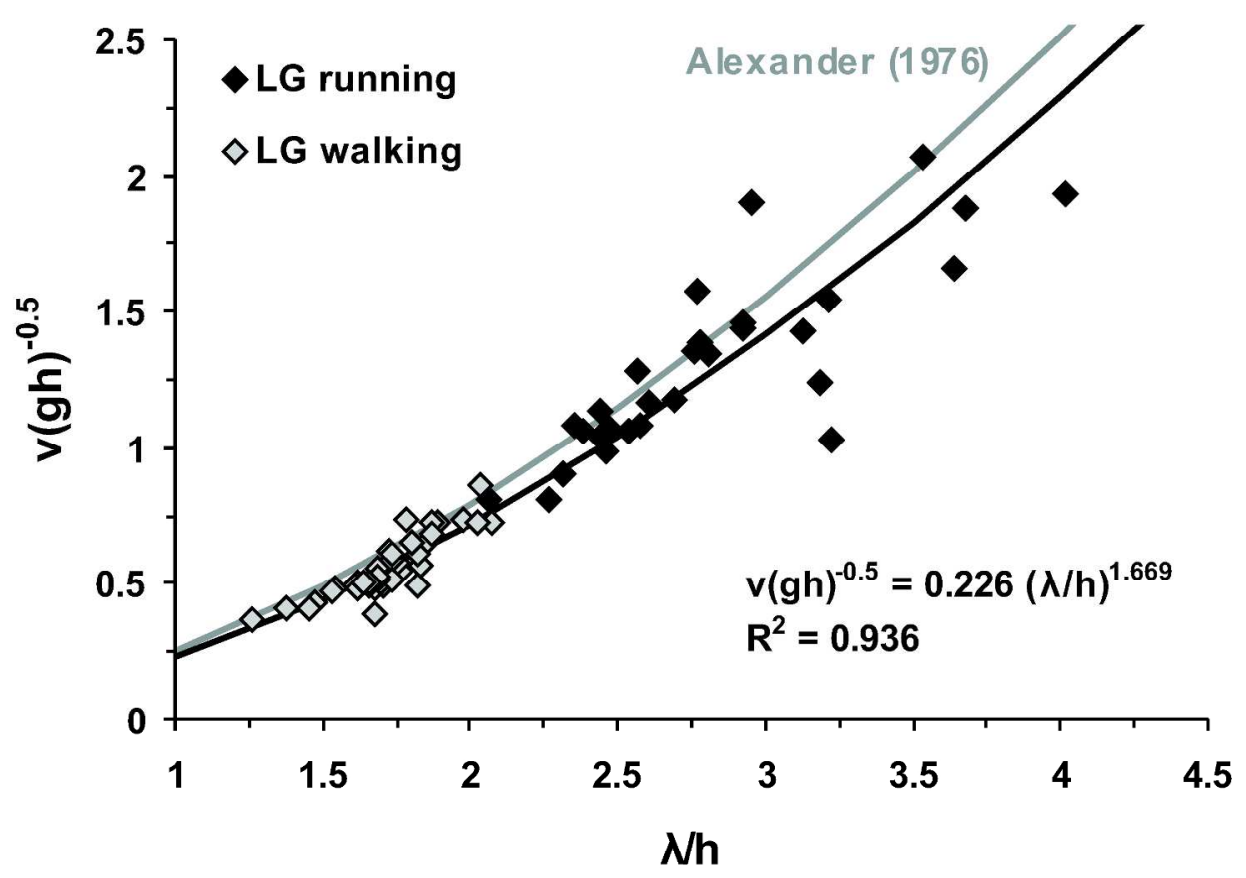

FIGURE 2. Non-dimensional speed (shown as the square root of the Froude number) as a function of the non-dimensional stride length for walking and running data (LG walking and LG running respectively) derived from the experiment at La Griega beach. Also shown are both the prediction from Alexander's (1976) methodology (gray curve), and the best fit power law for the experimental data (black curve). $751 \times 626 \mathrm{~mm}(96 \times 96 \mathrm{DPI})$ 
FIGURE 3. Ratio between the observed velocity and the theoretical velocity as a function of the nondimensional stride length, for the data obtained in the experiment at La Griega beach. The mean value (solid line) and standard deviations (dashed lines) are also shown. $100 \times 83 \mathrm{~mm}(300 \times 300 \mathrm{DPI})$ 


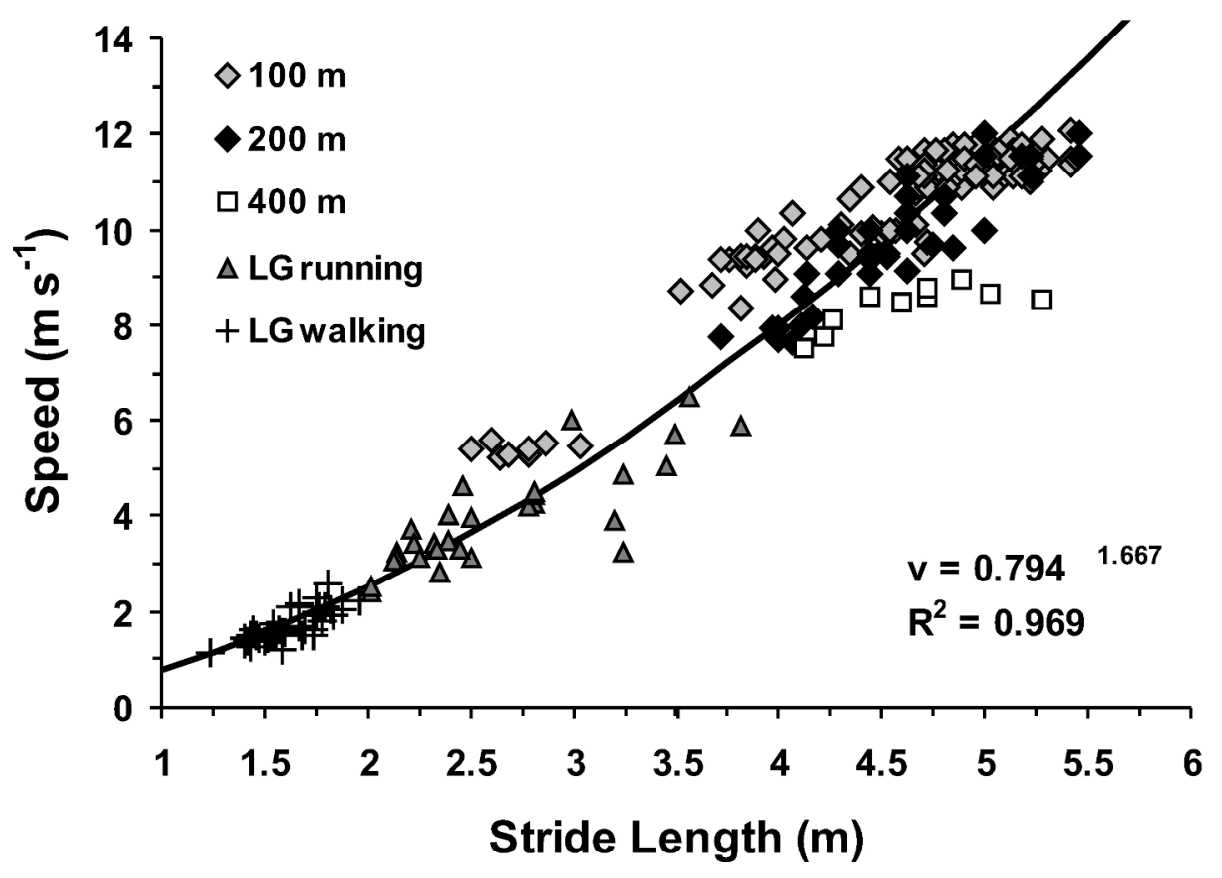

FIGURE 4. Speed as function of stride length for the whole set of data considered in this work. The best fit power law (black curve) is also shown. $750 \times 624 \mathrm{~mm}(96 \times 96 \mathrm{DPI})$ 


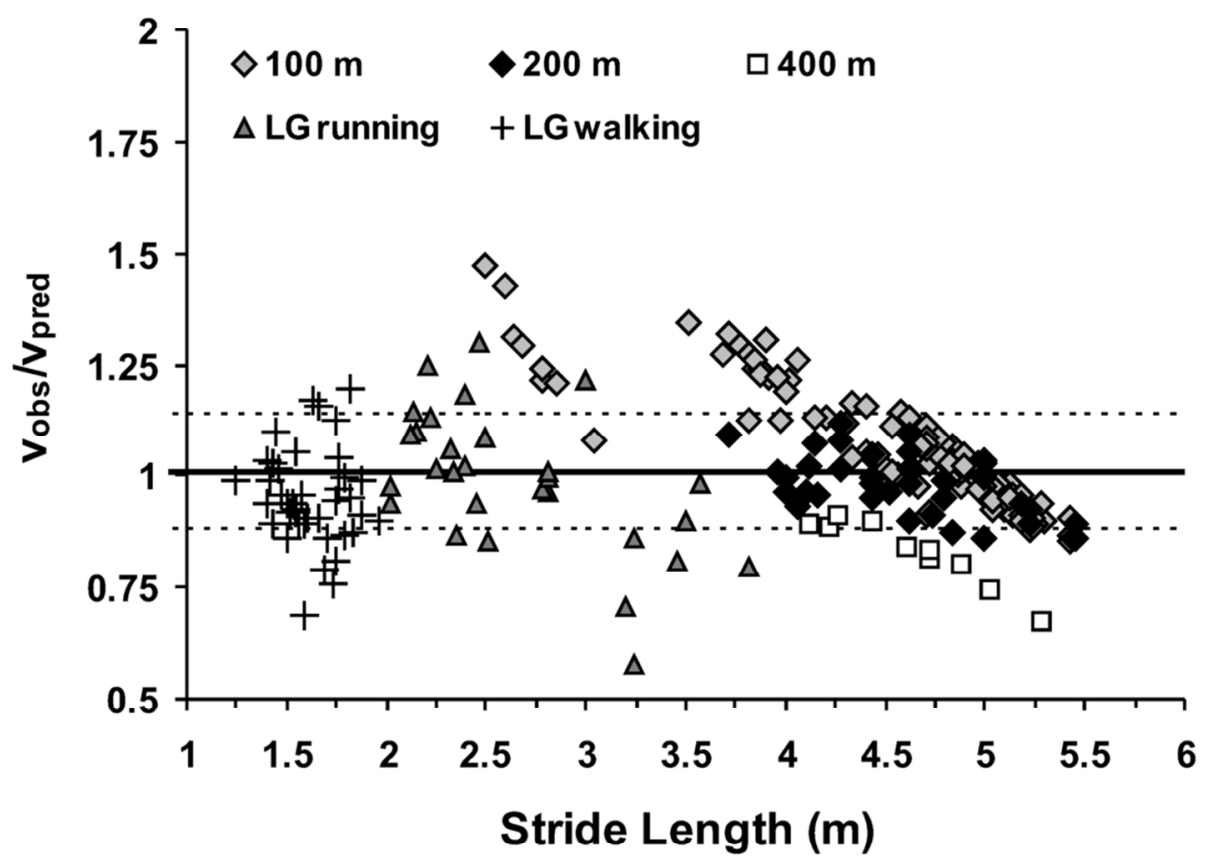

FIGURE 5. Ratio between the observed velocity and the velocity predicted by equation (4), as a function of the stride length, for the data included in Figure 4. The mean value (solid line) and standard deviations (dashed lines) are also shown. $99 \times 83 \mathrm{~mm}(300 \times 300$ DPI) 
Table 1. Stride length and velocity estimates for the Willandra Lakes human footprints.

\begin{tabular}{|c|c|c|c|}
\hline Trackways & $\begin{array}{c}\text { Stride Length } \\
(\mathbf{m})\end{array}$ & $\begin{array}{c}\text { Velocity (m s } \\
\text { (Webb, 2007) }\end{array}$ & $\begin{array}{c}\text { Velocity (m s } \\
\text { (this work) }\end{array}$ \\
\hline T0 (m) & 2.76 & 5.97 & $4.33(3.76-4.98)$ \\
\hline T1 (m) & 2.29 & 3.15 & $3.17(2.75-3.64)$ \\
\hline T2 (m) & 2.48 & 4.38 & $3.62(3.15-4.16)$ \\
\hline T3 (m) & 2.70 & 5.04 & $4.17(3.63-4.80)$ \\
\hline T4 (m) & 2.83 & 6.03 & - \\
\hline T5 (m) & 3.23 & 8.13 & $5.63(4.89-6.47)$ \\
\hline T6 (j) & 1.17 & 2.90 & $1.03(0.90-1.19)$ \\
\hline T7 (j) & 1.17 & 2.03 & $1.03(0.90-1.19)$ \\
\hline T8 (m) & 3.73 & 10.3 & $7.15(6.22-8.23)$ \\
\hline T9 (j) & 1.18 & 1.03 & $1.05(0.91-1.20)$ \\
\hline T10 (m) & 1.21 & 1.10 & $1.09(0.95-1.26)$ \\
\hline T11 (j) & 1.00 & 1.03 & $0.79(0.69-0.91)$ \\
\hline T12 (j) & 1.17 & 1.42 & $1.03(0.90-1.19)$ \\
\hline T13 (j) & 0.99 & 1.20 & $0.78(0.68-0.90)$ \\
\hline T14 (j) & 1.00 & 1.40 & $0.79(0.69-0.91)$ \\
\hline T15 (f) & 2.61 & 7.27 & $3.94(3.43-4.53)$ \\
\hline T16 (m?) & 2.90 & 9.10 & $4.70(4.09-5.40)$ \\
\hline T17 (m) & 2.12 & 3.28 & $2.78(2.42-3.20)$ \\
\hline T18 (f) & 1.23 & 1.19 & $1.12(0.98-1.29)$ \\
\hline T19 (f) & 1.60 & 2.19 & $1.74(1.51-2.00)$ \\
\hline T20 (m?) & 1.33 & 1.41 & $1.28(1.11-1.47)$ \\
\hline T21 (f) & 1.07 & 0.85 & $0.89(0.77-1.02)$ \\
\hline T22 (m) & 1.24 & 0.92 & $1.14(0.99-1.31)$ \\
\hline & & & \\
\hline
\end{tabular}

(m), (f) and (j) indicate male, female and juvenile individuals respectively; sex interpretation and stride length are after Webb (2007). Speed calculations performed using equation (4) are not presented for T4, since this trackways was originated by a one-leg individual. 